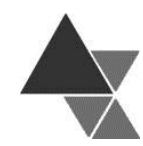

\title{
Estado nutricional e hábitos alimentares de universitários
}

\author{
Marina Paraluppi Loureiro ${ }^{1}$
}

É crescente o número de indivíduos portadores de sobrepeso e obesidade em inúmeros países, notadamente naqueles em desenvolvimento. Aliado a esse fato, ocorre a prevalência das doenças crônicas não transmissíveis (DCNT), associadas, frequentemente, aos maus hábitos alimentares e ao estilo de vida contemporâneo. Em virtude da escassez de revisões bibliográficas que abordem especificamente o estado nutricional e os hábitos alimentares de universitários e suas consequências, o presente artigo objetivou revisar pesquisas nacionais e internacionais que expusessem a problemática em questão, utilizando como ferramenta a Biblioteca Digital de Teses e Dissertações da Universidade de São Paulo, o Google Acadêmico e as bases de dados Scielo, Web of Science, Science Direct, Pub Med e Portal de Periódicos da Capes. Foram selecionados e analisados 27 estudos publicados entre 2002 e 2016, predominantemente de caráter transversal. Em relação aos estudos nacionais, optou-se por discutir, de uma forma mais detalhada, pelo menos um de cada região do país, tendo assim um melhor panorama dos fatos apontados no Brasil. Concluiu-se que a alimentação dos universitários apresentou-se inadequada, em virtude do expressivo consumo de alimentos processados e ultraprocessados e da decrescente ingestão de alimentos in natura, o que pode ocasionar diversos problemas de saúde.

Palavras-chaves: Estado Nutricional; Consumo Alimentar; Ingestão Dietética; IMC; Estudantes Universitários.

\section{Nutritional status and dietary habits of college students}

The number of individuals with overweight and obesity is increasing worldwide, notably in the developing countries. In addition, there is the prevalence of chronic non-communicable diseases (NCD) that are often associated to poor eating habits and the contemporary lifestyle. Due to the scarcity of bibliographical revisions that address specifically the nutritional status and dietary habits of college students and its consequences, this article aimed to review national and international research that exposed this issue. The Digital Library of theses and dissertations of the University of São Paulo, Google Scholar and Scielo databases, Web of Science, Science Direct, Pub Med and Capes Journal Portal were used as research tools. Twenty-seven studies published between 2002 and 2016, predominantly cross-sectional, were selected and analyzed. In relation to national studies, at least one from each region of the country was chosen for a more detailed discussion, thus having a better overview of the facts in Brazil. It was concluded that diet of academics is inadequate, due to significant consumption of processed and ultraprocessed foods, besides the lower intake of food products in natura, which can lead to various health problems.

Keywords: Nutritional Status; Food Consumption; Dietary Intake; BMI; University Students.

1 Graduanda em Ciências dos Alimentos, Universidade de São Paulo - USP, Escola Superior de Agricultura "Luiz de Queiroz" - ESALQ. Endereço para correspondência: Departamento de Agroindústria, Alimentos e Nutrição - Escola Superior de Agricultura "Luiz de Queiroz”, Universidade de São Paulo, Av. Pádua Dias no 11, CEP: 13418-900, Piracicaba, SP, Brasil. Telefone: +55 (19) 99392-7262. E-mail: marina.p.loureiro@gmail.com 


\section{INTRODUÇÃO}

Durante as duas últimas décadas, o número de indivíduos com sobrepeso ou obesidade aumentou cerca de três vezes nos países em desenvolvimento, basicamente em função da urbanização, do sedentarismo e do consumo de alimentos hipercalóricos ${ }^{[1]}$.

Em sua última Pesquisa de Orçamentos Familiares realizada entre 2008 e 2009 (POF 20082009), o Instituto Brasileiro de Geografia e Estatística (IBGE) constatou que cerca de 50,1\% dos homens e $48,0 \%$ das mulheres foram diagnosticados com excesso de peso, sendo que $63,8 \%$ da população adulta e $25,4 \%$ da população adolescente possuíam Índice de Massa Corporal (IMC) maior ou igual a $25 \mathrm{~kg} / \mathrm{m}^{2}[2]$.

Aliado ao crescimento do sobrepeso e da obesidade observa-se também a maior ocorrência de doenças crônicas, como a hipertensão arterial, O diabetes, o câncer e as doenças cardiovasculares. A maior incidência destas comorbidades está associada à diminuição do consumo de frutas e hortaliças, ao modo como os alimentos são preparados e ao consumo, em demasia, de alimentos processados, e acabam implicando em maiores gastos do governo com a saúde pública, além de afetar a vida de milhões de pessoas e seus familiares. Os referidos fatores colaboraram, de modo geral, para a prevalência das Doenças Crônicas Não-Transmissíveis (DCNT) na modernidade, aumentando a probabilidade de um indivíduo vir a desenvolver alguma destas enfermidades em algum período de sua vida ${ }^{[3,4]}$.

Segundo a Organização Mundial da Saúde (OMS), a adolescência é uma fase da vida que compreende a faixa etária dos 10 aos 19 anos [5]. De acordo com Jacobson [ $[$ é na adolescência que o indivíduo começa a tomar decisões a respeito de suas escolhas alimentares, sendo que estas decisões normalmente prevalecem durante a fase adulta. Isso faz com que este seja um período ideal para introduzir medidas preventivas de saúde [7].

Segundo Vieira et al. ${ }^{[8]}$, o estado nutricional do adolescente e seu desenvolvimento físico, psíquico e social estão atrelados às mudanças no comportamento alimentar, grau de atividade física, stress, consumo de álcool e nível de tabagismo. Jacobson [6] afirma, ainda, que o estado nutricional dos adolescentes também sofre a influência de fatores psicossociais, estilo de vida, modo de preparo dos alimentos, escolhas alimentares e doenças nutricionais.

O período de ingresso em uma universidade constitui uma importante etapa do processo de transição da adolescência para a fase adulta, já que é durante esse estágio da vida que a maioria dos adolescentes, antes acostumados ao convívio diário com suas famílias, deixam seus lares, passando, assim, a terem mais liberdade para tomarem suas próprias decisões e fazerem suas próprias escolhas. Somados a isso, eles devem, ainda, se adaptar à nova rotina e a nova carga horária de estudos e trabalhos, sendo que todas estas mudanças podem condicionar distúrbios, como o ganho de peso, durante esse período [9,10].

O ambiente universitário acaba dificultando a realização de uma alimentação saudável, balanceada e nutricionalmente rica, em virtude da carga de trabalhos acadêmicos, mudanças comportamentais apresentadas pelos indivíduos, stress, modismos dietéticos e inadequada administração do tempo ${ }^{[1,12]}$. Com isso, os estudantes acabam preferindo a realização de refeições rápidas, de fácil preparo ou prontas, sem horários definidos e de baixa qualidade nutricional, além de que, a omissão de algumas refeições justificada pela "falta de tempo" passa a ser bastante frequente ${ }^{[12] .}$

Desse modo, evidencia-se a importância da realização de programas que visem combater os maus hábitos alimentares da população universitária e instituir a promoção de incentivos para a prática de atividade física por esta população, como forma de prevenir o crescimento do número de indivíduos com excesso de peso ou portadores de doenças crônicas, durante os próximos estágios de vida ${ }^{[10]}$.

Devido à necessidade de revisões bibliográficas que contemplem o tema e o reconhecimento da sua importância para subsidiar ações de intervenção, o objetivo do presente artigo fundamentou-se na realização de uma revisão de literatura especializada sobre os temas "hábitos alimentares" e "estado nutricional de universitários". 


\section{METODOLOGIA}

A pesquisa por artigos científicos foi realizada utilizando as bases de dados bibliográficas Scielo, Web of Science, Pub Med, Portal de Periódicos Capes e Science Direct. Teses e dissertações foram obtidas por meio do acesso à Biblioteca Digital de Teses e Dissertações da USP e ao Google Acadêmico.

A busca por artigos ocorreu entre março e junho de 2016, utilizando as palavras-chaves: hábitos alimentares, consumo alimentar, estado nutricional, universitários, bem como seus derivados em inglês. Foram selecionados somente artigos publicados em língua inglesa, espanhola ou portuguesa, entre os anos de 2002 e 2016.

\section{RESULTADOS}

Os artigos selecionados para a presente revisão encontram-se registrados no Quadro 1, mostrado na sequência. 
Quadro 1. Características e desfechos dos estudos selecionados publicados entre os anos de 2002 e 2016

\begin{tabular}{|c|c|c|c|c|}
\hline Autoria e local do estudo & $\begin{array}{c}\text { Características da } \\
\text { amostra }\end{array}$ & $\begin{array}{c}\begin{array}{c}\text { Objetivo e tipo } \\
\text { do estudo }\end{array} \\
\end{array}$ & $\begin{array}{l}\text { Método de análise do consumo/hábito } \\
\text { alimentar }\end{array}$ & $\begin{array}{l}\text { Resultados } \\
\text { principais }\end{array}$ \\
\hline 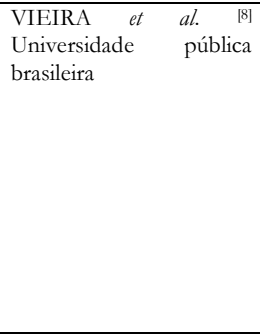 & $\begin{array}{l}185 \text { universitários ingressantes } \\
-106 \text { mulheres e } 79 \text { homens }\end{array}$ & $\begin{array}{l}\text { Analisar } \quad \text { perfil } \\
\text { socioeconômico, o estado } \\
\text { nutricional, as condições de } \\
\text { saúde, os hábitos alimentares e o } \\
\text { nível de atividade física dos } \\
\text { alunos. } \\
\text { Estudo transversal. }\end{array}$ & $\begin{array}{l}\text { Entrevistas com os acadêmicos, cujas } \\
\text { principais perguntas foram em relação ao } \\
\text { fracionamento da dieta, às refeições realizadas, } \\
\text { às rejeições alimentares, às mudanças na } \\
\text { alimentação e ao consumo semanal dos grupos } \\
\text { de alimentos. }\end{array}$ & $\begin{array}{l}\text { - menos da metade dos alunos realizavam algum tipo de atividade física; } \\
\text { - } 64 \% \text { relataram consumir bebidas alcóolicas eventualmente; } \\
\text { - cerca de } 60 \% \text { dos acadêmicos informaram não realizar as três refeições principais } \\
\text { diariamente; } \\
-72 \% \text { dos estudantes consumiam hortaliças ao menos cinco vezes na semana, } 75,1 \% \\
\text { ingeriam no máximo quatro porções semanais de frutas, enquanto que } 46,5 \% \text { afirmaram } \\
\text { consumir doces e gorduras ao menos cinco vezes na semana; } \\
-4,8 \% \text { dos alunos eram portadores de sobrepeso e obesidade. } \\
\text { - dos alunos eutróficos } 58,7 \% \text { possuíam porcentagens de gordura corporal superiores às } \\
\text { esperadas em relaçẫo a idade e ao sexo; } \\
\text { - foi relatado o aumento no consumo de alimentos após inserção na universidade por } \\
\text { quase } 50 \% \text { dos estudantes. }\end{array}$ \\
\hline $\begin{array}{l}\text { HUANG et al. }{ }^{[13]} \\
\text { Universidade do Kansas } \\
\text { (EUA) }\end{array}$ & $\begin{array}{l}736 \text { universitários }-\quad 382 \\
\text { homens e } 354 \text { mulheres. }\end{array}$ & $\begin{array}{l}\text { Avaliar hábitos alimentares, } \\
\text { estado nutricional e nível de } \\
\text { atividade física dos estudantes } \\
\text { Estudo transversal. }\end{array}$ & $\begin{array}{l}\text { Aplicação do questionário validado Berkeley } \\
\text { Screener com o intuito de avaliar a ingestão de } \\
\text { fibras, frutas e hortaliças, levando em } \\
\text { consideracãa a frequência de consumo destes } \\
\text { alimentos e seus derivados. Esta ferramenta é } \\
\text { utilizada para detectar indivínuos cujo } \\
\text { consumo de frutas e hortaliças é baixo e o } \\
\text { consumo de gorduras elevado. }\end{array}$ & $\begin{array}{l}\text { - menor consumo de fibras entre mulheres em comparaç̃ão aos homens; } \\
\text { - ingestão insuficiente de fibras, frutas e vegetais para ambos sexos; } \\
\text { - prática de atividade física inferior a } 3 \text { dias por semana entre os estudantes; } \\
\text { - } 21,6 \% \text { da população amostrada estava com sobrepeso e } 4,9 \% \text { era obesa, sendo que uma } \\
\text { maior porcentagem de indivíduos portadores de sobrepeso/obesidade foi encontrada } \\
\text { entre os homens. }\end{array}$ \\
\hline $\begin{array}{l}\text { BORGES e LIMA } \\
\text { FILHO }{ }^{[14]} \\
\text { Universidade Federal do } \\
\text { Mato Grosso do Sul }\end{array}$ & $\begin{array}{l}20 \text { universitários }-12 \text { do sexo } \\
\text { feminino e } 8 \text { do sexo } \\
\text { masculino. }\end{array}$ & $\begin{array}{l}\text { Observar os hábitos alimentares } \\
\text { dos estudantes. Estudo } \\
\text { qualitativo. }\end{array}$ & $\begin{array}{l}\text { Questionário semi-estruturado a respeito dos } \\
\text { hábitos alimentares, com perguntas relativas às } \\
\text { diferentes refeiçôes diárias e aos finais de } \\
\text { semana. }\end{array}$ & $\begin{array}{l}\text { - omissão do café da manhã considerada habitual; } \\
\text { - no almoço, as verduras e os legumes apresentaram uma menor preferência quando } \\
\text { comparados ao arroz, ao feijão e às carnes; } \\
\text { - omissão do almoço frequente para poucos estudantes } \\
\text { - para alguns alunos o jantar constituía a principal refeição do dia; } \\
\text { - nos finais de semana: aumento no consumo de massas, carnes e fast foods, bem como na } \\
\text { frequência das refeições realizadas fora de casa; } \\
\text { - os autores concluíram que inserção em uma faculdade promoveu alterações nos hábitos } \\
\text { alimentares destes estudantes. }\end{array}$ \\
\hline $\begin{array}{l}\text { ALVES e BOOG } \\
\text { Campinas - SP }\end{array}$ & $\begin{array}{l}100 \text { estudantes de graduação e } \\
\text { pós-graduação que residiam } \\
\text { em moradias universitárias - } \\
68 \text { homens e } 32 \text { mulheres. }\end{array}$ & $\begin{array}{l}\text { Relatar de forma detalhada, o } \\
\text { comportamento alimentar dos } \\
\text { indivíduos. Estudo quanti - } \\
\text { qualitativo. }\end{array}$ & $\begin{array}{l}\text { Recordatório alimentar de } 24 \text { horas contendo, } \\
\text { também, questões acerca do hábito e } \\
\text { frequência de compra de determinados } \\
\text { alimentos e do consumo alimentar na } \\
\text { república. }\end{array}$ & $\begin{array}{l}\text { - cerca de } 30 \% \text { dos universitários afirmaram omitir o café da manhã e } 20 \% \text { afirmaram } \\
\text { realizar um desjejum incompleto (ausência de alimentos reguladores ou alimentos fontes } \\
\text { de cálcio e energia); } \\
-72 \% \text { dos alunos relataram a realização de um almoço completo (com a presença de } \\
\text { alimentos fontes de proténas, energia, vitaminas e vegetais); } \\
\text { - o jantar foi classificado como incompleto por } 63 \% \text { dos estudantes; } \\
\text { - cerca de } 48 \% \text { dos acadêmicos não havia consumido nenhuma fruta no dia anterior a } \\
\text { pesquisa; } \\
\text { - cerca de } 22 \% \text { da população de estudantes afirmou nunca comprar hortaliças no } \\
\text { mercado, entretanto, alimentos como pão, bolachas e macarrão, eram adquiridos sempre } \\
\text { por, respectivamente, } 53 \%, 30 \% \text { e } 30 \% \text { da população. }\end{array}$ \\
\hline
\end{tabular}


Continuacão

\begin{tabular}{|c|c|c|c|c|}
\hline Autoria e local do estudo & $\begin{array}{l}\text { Características da } \\
\text { amostra }\end{array}$ & $\begin{array}{l}\text { Objetivo e tipo } \\
\text { do estudo }\end{array}$ & $\begin{array}{l}\text { Método de análise do consumo/hábito } \\
\text { alimentar }\end{array}$ & $\begin{array}{l}\text { Resultados } \\
\text { principais }\end{array}$ \\
\hline $\begin{array}{l}\text { FRANCA e COLARES } \\
\text { [16] Pernambuco }\end{array}$ & $\begin{array}{l}735 \text { alunos regularmente } \\
\text { matriculados em cursos da } \\
\text { área da saúde em duas } \\
\text { universidades públicas do } \\
\text { estado. Deste total, } 352 \text { alunos } \\
\text { estavam no primeiro semestre } \\
\text { e } 383 \text { estavam no último. } 511 \\
\text { mulheres e } 224 \text { homens. }\end{array}$ & $\begin{array}{l}\text { Realizar um estudo comparativo } \\
\text { de condutas de saúde entre } \\
\text { universitários que estavam no } \\
\text { início e no final dos cursos. } \\
\text { Estudo transversal. }\end{array}$ & $\begin{array}{l}\text { Aplicação do questionário National College } \\
\text { Health Risk Behavior Survey, que avalia, os } \\
\text { hábitos alimentares, a prática de atividade física } \\
\text { e as características sociodemográficas, bem } \\
\text { como outros fatores. }\end{array}$ & $\begin{array}{l}\text { - consumo de bebidas alcóolicas mais frequente entre os estudantes que estavam } \\
\text { concluindo a graduação; } \\
\text { - prática de atividade física significicativamente mais frequente entre aqueles que estavam } \\
\text { finalizando seu curso; } \\
\text { - quando se levou em consideração os hábitos alimentares gerais, não foram encontradas } \\
\text { diferenças significativas entre os grupos de alunos, porém o consumo de salgadinhos foi } \\
\text { significativamente menor para aqueles estudantes que se encontravam em períodos finais } \\
\text { de graduação; } \\
\text { - apesar de não terem sido encontradas diferenças significativas nos comportamentos } \\
\text { relacionados à saúde entre os universitários no início e no final de seus períodos de } \\
\text { graduação, os estudantes de semestres finais apresentaram, em geral, maiores percentuais } \\
\text { de hábitos negativos à saúde. }\end{array}$ \\
\hline $\begin{array}{l}\text { BRUNT et al. }{ }^{[17]} \\
\text { Canadá }\end{array}$ & $\begin{array}{l}557 \text { estudantes de graduação } \\
\text { de uma universidade } \\
\text { canadense }-334 \text { mulheres e } \\
223 \text { homens. }\end{array}$ & $\begin{array}{l}\text { Analisar a ingestão alimentar dos } \\
\text { universitários e verificar sua } \\
\text { relação com o } \text { IMC. Estudo } \\
\text { transversal. }\end{array}$ & $\begin{array}{l}\text { Questionário validado para a identificação dos } \\
\text { tipos (variedade) de alimentos ingeridos na } \\
\text { dieta (DVQ). O questionário continha } 42 \text { itens } \\
\text { usualmente consumidos pelos acadêmicos e } \\
\text { divididos por grupos de alimentos. Por } 3 \text { dias } \\
\text { os alunos foram solicitados a identificar quais } \\
\text { alimentos listados foram consumidos, sendo } \\
\text { um destes dias, referente ao fim de semana. }\end{array}$ & $\begin{array}{l}\text { - } 27 \% \text { dos indivíduos eram portadores de sobrepeso e cerca de } 8 \% \text { eram classificados } \\
\text { como obesos; } \\
\text { - elevada incidência de consumo de álcool e tabagismo; } \\
\text { - } 95 \% \text { dos estudantes consumiram ao menos duas porções de doces ou de alimentos } \\
\text { gordurosos durante os } 3 \text { dias de aplicação do questionário; } \\
\text { - a porcentagem dos universitários que consumiram apenas uma porção ou menos de } \\
\text { frutas, carnes, produtos lácteos, grãos e vegetais, nesse período, variou entre } 33 \% \text { e } 9 \% \\
\text { entre os grupos de alimentos; } \\
\text { - a existência de uma relacãa entre o consumo de alimentos e o IMC dos indivíduos foi } \\
\text { observada, sendo que indivíduos obesos ou com sobrepesos consumiam maiores } \\
\text { quantidade de carnes, enquanto aqueles que estavam abaixo do peso ingeriram mais } \\
\text { hortalicas, cereais e produtos lácteos. }\end{array}$ \\
\hline $\begin{array}{l}\text { MARCONDELLI, } \\
\text { COSTA e SCHIMITZ [18] } \\
\text { Universidade de Brasilia }\end{array}$ & $\begin{array}{l}281 \text { estudantes matriculados } \\
\text { entre os } 3^{\circ} \text { e } 5^{\circ} \text { semestres de } \\
\text { cursos de graduação na área da } \\
\text { saúde }-182 \text { mulheres e } 99 \\
\text { homens. }\end{array}$ & 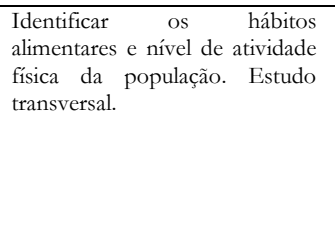 & $\begin{array}{l}\text { Questionário elaborado especialmente para o } \\
\text { estudo e validado em escala piloto, contendo } \\
\text { questões sobre os hábitos alimentares, prática } \\
\text { de atividade física, dados antropométricos e } \\
\text { porções de alimentos, constituintes da } \\
\text { pirâmide alimentar, consumidas. }\end{array}$ & $\begin{array}{l}\text { - } 10 \% \text { dos estudantes eram portadores de sobrepeso e } 1,4 \% \text { eram obesos; } \\
-65,5 \% \text { dos indivíduos foram classificados como sedentátios; } \\
-40 \% \text { declarou consumir bebidas alcóolicas ao menos uma vez por semana; } \\
\text { - em relação aos hábitos alimentares, o consumo de frutas e hortaliças, leite e derivados } \\
\text { e fibras encontrou-se inadequado para, respectivamente, } 24,9 \% \text {, } 23,1 \% \text { e } 25,9 \% \text { dos } \\
\text { estudantes, entretanto, o consumo inadequado de refrigerantes e doces foi relatado para } \\
70 \% \text { da população; } \\
-79,7 \% \text { dos estudantes tiveram suas dietas caracterizadas como inadequadas. }\end{array}$ \\
\hline $\begin{array}{l}\text { MONTEIRO et al. }{ }^{[11]} \\
\text { Minas Gerais }\end{array}$ & $\begin{array}{l}47 \text { acadêmicas dos cursos de } \\
\text { Nutrição e Enfermagem da } \\
\text { Universidade Federal de Minas } \\
\text { Gerais. }\end{array}$ & $\begin{array}{l}\text { Identificar o hábito e consumo } \\
\text { alimentar destas estudantes. } \\
\text { Estudo transversal. }\end{array}$ & $\begin{array}{l}\text { Questionário de Frequência Alimentar } \\
\text { Qualitativo adaptado para a dieta da população } \\
\text { brasileira. Os alimentos presentes no } \\
\text { questionário foram classificados em grupos. } \\
\text { Aqueles alimentos consumidos por no mínimo } \\
50 \% \text { da população foram considerados como } \\
\text { integrantes do hábito alimentar. }\end{array}$ & $\begin{array}{l}\text { - } 76,6 \% \text { das estudantes declararam estarem descontentes com sua alimentação; } \\
\text { - o consumo de frutas e hortaliças foi considerado baixo; } \\
\text { - as hortaliças mais consumidas pelas estudantes foram, a alface e o tomate. Quanto as } \\
\text { frutas, as mais consumidas foram a banana, as frutas cítricas, a maçã e o mamão; } \\
\text { - alimentos como lasanha, bolos, pizzas e bolachas também apresentaram consumo } \\
\text { expressivo; } \\
\text { - lanches naturais, salgados assados e fritos, cachorro quente, alimentos provenientes de } \\
\text { lanchonetes e chips apresentaram consumo elevado e o refrigerante teve seu consumo } \\
\text { relatado ao menos uma vez na semana por } 57,8 \% \text { das entrevistadas; } \\
\text {-alto consumo de açúcares, lipídeos e pães identificado nas dietas. }\end{array}$ \\
\hline
\end{tabular}


Continuação

\begin{tabular}{|c|c|c|c|c|}
\hline Autoria e local do estudo & $\begin{array}{l}\text { Características da } \\
\text { amostra }\end{array}$ & $\begin{array}{l}\text { Objetivo e tipo } \\
\text { do estudo }\end{array}$ & $\begin{array}{l}\text { Método de análise do consumo/hábito } \\
\text { alimentar }\end{array}$ & $\begin{array}{l}\text { Resultados } \\
\text { principais }\end{array}$ \\
\hline $\begin{array}{l}\text { PETRIBÚ, CABRAL e } \\
\text { ARRUDA [19] } \\
\text { Recife - PE }\end{array}$ & $\begin{array}{l}250 \text { alunos de cursos de } \\
\text { graduação na área da saúde em } \\
\text { uma universidade pública, } \\
\text { sendo } 154 \text { mulheres e } 96 \\
\text { homens. }\end{array}$ & $\begin{array}{lrr}\text { Enfatizar } & \text { os } & \text { aspectos } \\
\text { nutricionais } & \text { como fatores de } \\
\text { risco para o desenvolvimento de } \\
\text { doenças } & \text { cardiovasculares. } \\
\text { Estudo transversal. }\end{array}$ & $\begin{array}{l}\text { Recordatório de } 24 \text { horas utilizado para avaliar } \\
\text { a ingestão de macronutrientes e o perfil de } \\
\text { lipídeos da dieta (conteúdos de gordura } \\
\text { saturada, colesterol, ácidos graxos poli- } \\
\text { insaturados e monoinsaturados e ácido } \\
\text { linoleico). As medidas caseiras foram } \\
\text { convertidas em gramas através de tabela de } \\
\text { referência. }\end{array}$ & $\begin{array}{l}\text { - as mulheres eram mais sedentárias que os homens, contudo, entre os homens o número } \\
\text { de indivíduos do sexo masculino que apresentava IMC superior a } 25 \mathrm{~kg} / \mathrm{m}^{2} \text { foi maior que } \\
\text { o encontrado para o sexo feminino; } \\
\text { - a população amostrada possúá uma alimentação com proporções inadequadas de } \\
\text { energia, porém, o percentual de inadequação para a ingestão de nutrientes como } \\
\text { carboidratos e proténas foi baixo; } \\
\text { - } 95 \% \text { da população de estudantes apresentavam baixos níveis de ingestão de ácidos } \\
\text { graxos insaturados, estando estes valores inferiores ao recomendado, entretanto, foram } \\
\text { encontrados, elevados índices de ingestão de nutrientes ligados às doenças } \\
\text { cardiovasculares como colesterol e gordura saturada para grande parte dos estudantes. }\end{array}$ \\
\hline $\begin{array}{llll}\text { FEITOSA } & \text { et } & \text { al. } & {[20]} \\
\text { Sergipe } & & & \end{array}$ & $\begin{array}{l}718 \text { estudantes da } \\
\text { Universidade Federal do } \\
\text { Sergipe } \quad \text { regularmente } \\
\text { matriculados em cursos das } \\
\text { áreas de saúde, exatas e } \\
\text { humanas, sendo } 360 \text { mulheres } \\
\text { e } 358 \text { homens. }\end{array}$ & 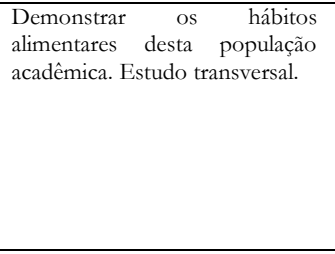 & $\begin{array}{l}\text { Adaptação do questionário "Como está sua } \\
\text { alimentação" proposto pelo Ministério da } \\
\text { Saúde. A ferramenta aplicada continha } \\
\text { questões quantitativas (referentes a frequência } \\
\text { de consumo dos alimentos) e qualitativas } \\
\text { (referentes aos comportamentos alimentares). } \\
\text { Posterior comparação com as recomendações } \\
\text { do Guia Alimentar e da Pirâmide Alimentar } \\
\text { Adaptada para a População Brasileira. }\end{array}$ & $\begin{array}{l}\text { - 17,9\% da populaç̃o apresentavam sobrepeso ou obesidade; } \\
\text { - de forma geral, os alunos de ambos sexos apresentaram baixo consumo de frutas e } \\
\text { hortaliças não atingindo os valores preconizados; } \\
\text { - quanto ao consumo de leguminosas e carnes, grande parte dos alunos, de modo geral, } \\
\text { ingeriram as quantidades recomendadas para estes respectivos alimentos } \\
\text { - grande parte da população amostrada praticava comportamentos alimentares } \\
\text { apropriados, procurando remover a gordura visível na carne, reduzir o consumo de } \\
\text { frituras, doces e embutidos, não trocar refeições por lanches e consumir bebidas } \\
\text { alcóolicas com moderação. }\end{array}$ \\
\hline $\begin{array}{l}\text { MATIAS E FIORE }{ }^{[21]} \\
\text { Guarulhos - SP }\end{array}$ & $\begin{array}{l}35 \text { universitários regularmente } \\
\text { matriculados no curso de } \\
\text { nutrição de uma universidade } \\
\text { brasileira privada. }\end{array}$ & $\begin{array}{l}\text { Investigar as mudanças } \\
\text { ocorridas no comportamento } \\
\text { alimentar dos alunos durante o } \\
\text { decorrer da graduação. } \\
\text { Estudo longitudinal. }\end{array}$ & $\begin{array}{l}\text { Questionário de Frequência Alimentar } \\
\text { contendo } 36 \text { alimentos e questão fechada sobre } \\
\text { às refeições diárias. Posterior comparação com } \\
\text { as recomendações da Pirâmide Alimentar } \\
\text { Adaptada à População Brasileira. }\end{array}$ & $\begin{array}{l}\text { - de modo geral, no quarto ano de graduação, o consumo alimentar destes estudantes } \\
\text { melhorou, em comparação ao período que se encontravam no primeiro ano; } \\
\text { - no quarto ano de graduação, os alunos consumiram, mais frequentemente, alimentos } \\
\text { dos grupos dos cereais, leguminosas, frutas, hortaliças e carnes, bem como diminuíram o } \\
\text { consumo de alimentos pertencentes as categorias dos doces e gorduras } \\
\text { - quanto a frequência de refeições, os indivíduos do último ano realizaram as mesmas } \\
\text { (café da manhana,almoço e jantar) de forma mais frequente, enquanto que a frequência dos } \\
\text { beliscos foi reduzida; } \\
\text { - inadequacõoses alimentares como insuficiente consumo de frutas, hortaliças, leite e } \\
\text { derivados ainda foram observadas para mais de } 60 \% \text { dos estudantes. }\end{array}$ \\
\hline $\begin{array}{lr}\text { ANSARI, STOCK } & \text { e } \\
\text { MIKOLAJCZYK } & {[22]} \\
\text { Alemanha, Polônia, } \\
\text { Bulgária e Dinamarca }\end{array}$ & $\begin{array}{l}2.402 \quad \text { universitários } \\
\text { matriculados no primeiro ano } \\
\text { de graduação em cursos de } \\
\text { universidades destes países. }\end{array}$ & $\begin{array}{ll}\text { Investigar o consumo alimentar } \\
\text { dos estudantes. Estudo } \\
\text { transversal. }\end{array}$ & $\begin{array}{l}\text { Questionário de frequência alimentar adaptado } \\
\text { para o estudo, contendo uma questão } \\
\text { introdutória referente a frequência de consumo } \\
\text { dos alimentos citados. }\end{array}$ & $\begin{array}{l}\text { - os estudantes búlgaros consumiam, com maior frequência bolos, doces, fast foods e snacks, } \\
\text { bem como alimentos considerados saudáveis (saladas, hortaliças e peixes); } \\
\text { - o consumo de carnes, demonstrou-se elevado entre os acadêmicos dos quatro países; } \\
\text { - menos de metade dos indivíduos inseridos no estudo relataram o consumo constante } \\
\text { de frutas; } \\
\text { - o consumo de alimentos pertencentes aos grupos das carnes, frutas e vegetais, foi menor } \\
\text { entre os indivíduos que não residiam na casa dos pais quando comparados àqueles que } \\
\text { residiam. }\end{array}$ \\
\hline
\end{tabular}


Continuação

\begin{tabular}{|c|c|c|c|c|}
\hline Autoria e local do estudo & $\begin{array}{l}\text { Características da } \\
\text { amostra }\end{array}$ & $\begin{array}{l}\text { Objetivo e tipo } \\
\text { do estudo }\end{array}$ & $\begin{array}{l}\text { Método de análise do consumo/hábito } \\
\text { alimentar }\end{array}$ & $\begin{array}{l}\text { Resultados } \\
\text { principais }\end{array}$ \\
\hline $\begin{array}{llll}\text { MACIEL et } & \text { al. } & {[23]} \\
\text { Piracicaba } & \text { SPP } & & \end{array}$ & $\begin{array}{l}303 \text { estudantes }-130 \\
\text { acadêmicos e } 173 \text { acadêmicas } \\
\text { da Escola Superior de } \\
\text { Agricultura 'Luiz de Queiroz'. }\end{array}$ & $\begin{array}{l}\text { Identificar o consumo alimentar } \\
\text { dos universitários, bem como o } \\
\text { estado nutricional e o nível de } \\
\text { atividade física desta população } \\
\text { em questão. Estudo transversal. }\end{array}$ & $\begin{array}{l}\text { Questionário de frequência alimentar com } \\
\text { porções padronizadas, aplicado com o intuito } \\
\text { de identificar a frequência do consumo de } \\
\text { alimentos/grupos de alimentos pelos } \\
\text { acadêmicos durante } 15 \text { dias. }\end{array}$ & $\begin{array}{l}\text { - 72,3\% da população feminina e somente } 47,7 \% \text { da população masculina apresentaram } \\
\text { IMC classificado como normal; } \\
\text { - casos de obesidade mórbida (grau 3) foram encontrados na população masculina; } \\
\text { - a população feminina apresentou maior nível de atividade física; } \\
\text { - a população universitária não apresentou boa frequência no consumo de cereais e } \\
\text { leguminosas e na ingestão de frutas e hortaliças, não atingindo as recomendações } \\
\text { preconizadas; } \\
\text { - não foi encontrada uma correlação entre o estado nutricional (IMC), o nível de atividade } \\
\text { física e o consumo alimentar dos indivíduos analisados }\end{array}$ \\
\hline $\begin{array}{l}\text { RAMALHO, } \\
\text { DALAMARIA } \\
\text { SOUZA [24] } \\
\text { Rio Branco - AC }\end{array}$ & $\begin{array}{l}863 \text { universitários } \\
\text { matriculados em cursos da } \\
\text { Universidade Federal do Acre. } \\
330 \text { homens e } 533 \text { mulheres. }\end{array}$ & $\begin{array}{l}\text { Estudar o consumo de frutas e } \\
\text { hortaliças por esta população. } \\
\text { Estudo transversal. }\end{array}$ & $\begin{array}{l}\text { Questionário estruturado contendo perguntas } \\
\text { a respeito dos hábitos alimentares (frequência } \\
\text { semanal de consumo dos alimentos de } \\
\text { diferentes grupos), entre outros fatores. O } \\
\text { consumo de frutas e hortaliças por } 4 \text { ou menos } \\
\text { vezes na semana foi caracterizado como } \\
\text { irregular. }\end{array}$ & $\begin{array}{l}\text { - somente } 14,8 \% \text { dos estudantes consumiam regularmente frutas e hortaliças, sendo que } \\
\text { a quantidade ingerida de hortaliças era praticamente o dobro da ingerida de frutas; } \\
\text { - os estudantes mais velhos consumiam mais vegetais em comparação aos mais jovens; } \\
\text { - indivíduos pertencentes às classes A e B, apresentaram probabilidade de consumir frutas } \\
\text { e hortaliças cerca de } 1,7 \text { vezes maior, quando comparados aos indivíduos das classes } \mathrm{C} \text { e } \\
\text { D; } \\
\text { - houve uma relação entre o consumo regular de frutas e hortaliças e o fato destes } \\
\text { acadêmicos serem ativos fisicamente e consumirem fast foods no máximo duas vezes por } \\
\text { semana. }\end{array}$ \\
\hline $\begin{array}{llll}\text { BURRIEL } & \text { et } & \text { al. } & \text { [25] } \\
\text { Espanha } & & & \\
\end{array}$ & $\begin{array}{lrr}80 \text { alunos } & \text { do curso de } \\
\text { enfermagem } & \text { de } & \text { uma } \\
\text { universidade } & \text { espanhola. } 63 \\
\text { mulheres e } 17 \text { homens. }\end{array}$ & $\begin{array}{l}\text { Analisar a dieta e e o estado } \\
\text { nutricional destes universitários. } \\
\text { Estudo transversal. }\end{array}$ & $\begin{array}{l}\text { Emprego de } 9 \text { recordatórios alimentares de } 24 \\
\text { horas aplicados por } 3 \text { dias durante os meses de } \\
\text { fevereiro, maio e outubro. A qualidade da dieta } \\
\text { foi avaliada através do índice de alimentação } \\
\text { saudável (IAS). }\end{array}$ & $\begin{array}{l}\text { - a maioria dos estudantes apresentavam valores de IMC considerados adequados, } \\
\text { entretanto cerca de } 6,3 \% \text { das mulheres apresentaram baixo peso e } 17 \% \text { dos homens } \\
\text { foram classificados com sobrepeso; } \\
\text { - a dieta dos universitários foi, de modo geral, caracterizada como hipocalórica, } \\
\text { hiperproteica e pobre em carboidratos, porém o consumo de açúcares simples foi } \\
\text { elevado; } \\
\text { - o consumo de gorduras entre os universitários foi, também, alto, bem como a ingestão } \\
\text { de gorduras saturadas e colesterol. Já o consumo de fibras foi baixo, assim como a } \\
\text { ingestão de frutas e legumes; } \\
\text { - a dieta destes estudantes apresentava baixo índice de saudabilidade, sendo que mudanças } \\
\text { seriam necessárias em mais de } 90 \% \text { dos casos. }\end{array}$ \\
\hline $\begin{array}{l}\text { GASPAROTTO et al. [26] } \\
\text { Paraná }\end{array}$ & $\begin{array}{l}1.599 \text { alunos de cursos de } \\
\text { graduação da Universidade } \\
\text { Federal do Paraná; } 1197 \\
\text { ingressantes e } 402 \text { formandos. }\end{array}$ & $\begin{array}{l}\text { Identificar fatores de riscos } \\
\text { cardiovasculares entre a } \\
\text { população e compará-los com } \\
\text { relação ao sexo, períodos de } \\
\text { graduação e áreas de estudo, } \\
\text { avaliando, para isso, o estado } \\
\text { nutricional e consumo alimentar, } \\
\text { entre outros fatores Estudo } \\
\text { transversal. }\end{array}$ & $\begin{array}{l}\text { Questões a respeito das porções ingeridas de } \\
\text { alimentos (hortaliças, frutas, salgados e bolos) } \\
\text { no dia anterior à pesquisa } O \text { ponto de corte } \\
\text { adotado para o consumo de frutas e hortaliças } \\
\text { foi de } 3 \text { porçõos para cada um, conforme } \\
\text { sugerido no Dietary Guildelines for Americans. }\end{array}$ & $\begin{array}{l}\text { - apenas } 13,8 \% \text { consumiram, ao menos, seis porções de frutas e vegetais no dia anterior } \\
\text { à pesquisa, enquanto } 34,6 \% \text { consumiram salgadinhos; } \\
\text { - a população masculina apresentava maior tempo gasto com atividade física moderada } \\
\text { ou vigorosa quando comparada a feminina, apesar de apresentar maiores valores de IMC } \\
\text { e uma menor ingestão de frutas e hortaliças; } \\
\text { - as mulheres apresentaram ingestão maior de doces; } \\
\text { - os alunos dos primeiros anos, apresentaram maior tempo desprendido para a realização } \\
\text { de atividade física média ou vigorosa; } \\
\text { - estudantes de Biológicas gastavam tempos maiores com a prática de atividade física. } \\
\text { Estudantes de Exatas apresentavam maior ingestão de bebidas alcóolicas e maiores } \\
\text { valores de IMC. Estudantes de Humanas relataram menor tempo dedicado à prática de } \\
\text { exerć́cio físico. }\end{array}$ \\
\hline
\end{tabular}


Continuacão

\begin{tabular}{|c|c|c|c|c|}
\hline Autoria e local do estudo & $\begin{array}{l}\text { Características da } \\
\text { amostra }\end{array}$ & $\begin{array}{l}\text { Objetivo e tipo } \\
\text { do estudo }\end{array}$ & $\begin{array}{l}\text { Método de análise do consumo/hábito } \\
\text { alimentar }\end{array}$ & $\begin{array}{l}\text { Resultados } \\
\text { principais }\end{array}$ \\
\hline $\begin{array}{l}\text { SILVA E BUSNELLO } \\
\text { [27] } \\
\text { Rio Grande do Sul }\end{array}$ & $\begin{array}{l}104 \text { universitários. } \\
101 \text { mulheres e } 3 \text { homens. }\end{array}$ & $\begin{array}{l}\text { Conhecer os hábitos alimentares } \\
\text { de estudantes matriculados no } \\
\text { curso de nutrição da } \\
\text { Universidade Regional do } \\
\text { Noroeste do Estado do Rio } \\
\text { Grande do Sul. Estudo } \\
\text { quantitativo descritivo. }\end{array}$ & $\begin{array}{l}\text { Questionário "Como está sua alimentação" } \\
\text { proposto pelo Ministério da Saúde sobre } \\
\text { alimentação saudável. Comparação e } \\
\text { classificação do consumo diário de } \\
\text { carnes/ovos, frutas, hortalicas e leguminosas } \\
\text { de acordo com a Pirâmide Alimentar Adaptada } \\
\text { para a População Brasileira. Consumo de leite } \\
\text { classificado de acordo com o Guia Alimentar. }\end{array}$ & $\begin{array}{l}\text { - apenas } 20,2 \% \text { dos alunos relataram consumir ao menos três porções diárias de frutas; } \\
\text { - em relação ao consumo de verduras e legumes, apenas } 4,8 \% \text { consumiam, diariamente, } \\
\text { oito ou mais colheres de sopa; } \\
\text { - o consumo irregular de leite e derivados foi encontrado para } 88,4 \% \text { dos alunos; } \\
\text { - quanto as práticas alimentares, } 89,5 \% \text { da população informou remover a camada visível } \\
\text { de gordura das carnes e } 97,1 \% \text { afirmou não acrescentar mais sal aos alimentos, entretanto } \\
67,6 \% \text { relatou consumir bebidas alcóolicas, } 89,5 \% \text { informou ter o hábito de consumir } \\
\text { doces e bebidas industrializadas e } 77,1 \% \text { apresentou o costume de ingerir embutidos, } \\
\text { frituras e salgadinhos. }\end{array}$ \\
\hline $\begin{array}{l}\text { FERREIRA, OLIVEIRA } \\
\text { e REGGIOLLI [28] Mogi } \\
\text { Guaçu - SP }\end{array}$ & $\begin{array}{l}560 \text { estudantes matriculados } \\
\text { em cursos de diferentes áreas } \\
\text { de uma universidade privada } \\
\text { da cidade. } \\
312 \text { mulheres e } 248 \text { homens. }\end{array}$ & $\begin{array}{l}\text { Apontar os tipos de alimentos } \\
\text { ingeridos pelos alunos durante o } \\
\text { lanche. Estudo transversal. }\end{array}$ & $\begin{array}{l}\text { Questionário contendo perguntas sobre } \\
\text { consumo alimentar (quais refeições eram } \\
\text { realizadas, quais alimentos eram ingeridos, } \\
\text { horários de consumo e procedência). }\end{array}$ & $\begin{array}{l}\text { - } 93 \% \text { dos alunos afirmaram almoçar, } 70 \% \text { realizavam o desjejum, } 58 \% \text { jantavam, } \\
\text { enquanto apenas } 36 \%, 20 \% \text { e } 15 \% \text { relataram realizar o lanche da tarde, a ceia e o lanche } \\
\text { da manhã; } \\
\text { - os alimentos mais frequentemente ingeridos no intervalo das aulas foram os salgados } \\
\text { assados, os refrigerantes, os lanches e os chocolates; } \\
\text { - alimentos como bolachas salgadas, bolachas recheadas e barras de cereal foram também } \\
\text { mencionados, porém apresentaram consumo menor; } \\
-55 \% \text { dos estudantes afirmaram comprar alimentos de baixa qualidade nutricional na } \\
\text { própria cantina da faculdade e } 13 \% \text { relataram adquiri-los de comerciantes que vendiam } \\
\text { produtos dentro da própria instituição de ensino. }\end{array}$ \\
\hline $\begin{array}{l}\text { PELTZER et al. }{ }^{[1]} \\
22 \text { países emergentes ou } \\
\text { de baixa ou média renda }\end{array}$ & $\begin{array}{l}15.746 \quad \text { universitários } \\
\text { regularmente matriculados em } \\
\text { cursos de diversas áreas, sendo } \\
8913 \text { mulheres e } 6773 \text { homens. }\end{array}$ & $\begin{array}{l}\text { Identificar o predomínio do } \\
\text { sobrepeso e da obesidade na } \\
\text { população. Estudo transversal. }\end{array}$ & $\begin{array}{l}\text { O consumo de frutas e hortaliças foi avaliado } \\
\text { através da questão "Quantas porções de } \\
\text { frutas/hortaliças você costuma consumir?" e } \\
\text { classificado como insuficiente quando a } \\
\text { ingestão destes alimentos era inferior a } 5 \\
\text { porções/dia. Foram também investigadas a } \\
\text { frequência de consumo de carnes vermelhas, a } \\
\text { realização de café da manhã e lanches entre as } \\
\text { refeições, entre outros fatores. }\end{array}$ & $\begin{array}{l}\text { - um total de } 22 \% \text { da população amostrada apresentou problemas de excesso de peso, } \\
\text { sendo, este problema, significativamente maior entre a população masculina, embora a } \\
\text { mesma fosse mais ativa fisicamente; } \\
\text { - em geral, habitar um país com maior renda esteve significativamente associado com a } \\
\text { prevalência do excesso de peso; } \\
\text { - quanto as varíveis dietéticas } 22,5 \% \text { da população relatou ingerir carne vermelha ao } \\
\text { menos uma vez ao dia, } 21,9 \% \text { apresentou consumo irregular de frutas e hortaliças, } 25,2 \% \\
\text { relatou tentar reduzir o consumo de gorduras e colesterol e } 24,1 \% \text { mencionaram tentar } \\
\text { aumentar o consumo de fibras. }\end{array}$ \\
\hline $\begin{array}{llll}\text { BUSATO et } & \text { al. } & {[29]} \\
\text { Chapecó - SC } & & \end{array}$ & $\begin{array}{l}175 \text { universitários } \\
\text { matriculados em cursos da } \\
\text { Universidade Comunitária da } \\
\text { Região de Chapecó. } 142 \\
\text { mulheres e } 33 \text { homens. }\end{array}$ & $\begin{array}{lrr}\begin{array}{l}\text { Descrever } \\
\text { alimentares }\end{array} & \text { destes } & \text { práticas } \\
\text { Estudo } & \text { obsudantes. } \\
\text { prospectivo. } & & \end{array}$ & $\begin{array}{llrl}\text { Questionário } & \text { estruturado } & \text { utilizado para } \\
\text { identificação dos hábitos } & \text { alimentares e } \\
\text { percepção do ambiente e alimentação saudável. }\end{array}$ & $\begin{array}{l}\text { - para } 89 \% \text { da população, o almoço consistiu na refeição mais importante do dia e os } \\
\text { alimentos frequentemente ingeridos, nesta refeição, foram o arroz, o feijão, a carne e os } \\
\text { vegetais, na forma de salada; } \\
\text { - } 62 \% \text { dos alunos afirmaram substituir o jantar por refeições mais leves ou sanduíches; } \\
\text { - o café da manhã apresentou-se como a refeição mais omitida e incompleta; } \\
\text { - cerca de } 54 \% \text { dos alunos afirmaram, ainda, consumir frituras e } 51 \% \text { relataram o } \\
\text { consumo de doces uma vez por semana; } \\
\text { - apenas } 39 \% \text { dos estudantes consumiam frutas e hortaliças diariamente. }\end{array}$ \\
\hline $\begin{array}{llll}\text { FARIA et } & \text { al. } & \text { [30] } \\
\text { Umuarama }-\mathrm{MG} & \end{array}$ & $\begin{array}{l}20 \text { estudantes de diversos } \\
\text { cursos da Universidade } \\
\text { Federal de Uberlândia. } \\
13 \text { mulheres e } 7 \text { homens. }\end{array}$ & $\begin{array}{l}\text { Definir os hábitos e escolhas } \\
\text { alimentares dos acadêmicos. } \\
\text { Estudo qualitativo. }\end{array}$ & $\begin{array}{l}\text { Realização de estudo de campo exploratório } \\
\text { que visava identificar as escolhas e } \\
\text { comportamentos alimentares. O instrumento } \\
\text { Diagnóstico das Práticas e Comportamentos } \\
\text { Alimentares foi utilizado como base para a } \\
\text { entrevista. }\end{array}$ & $\begin{array}{l}\text { - apenas 5\% declarou fazer seis refeições por dia, sendo que a maioria }(25 \%) \text { relatou fazer } \\
\text { quatro refeições; } \\
\text { - no jantar apenas } 40 \% \text { preferiram consumir arroz, feijão, carne e salada, frente a } 60 \% \\
\text { que mencionaram substituir estes alimentos por salgados e lanches; } \\
\text { - quanto aos locais escolhidos para realização do almoço, a maioria }(70 \%) \text { preferiu o } \\
\text { restaurante universitário, entretanto outros locais também foram listados, como as } \\
\text { lanchonetes dentro do campus, os restaurantes ao redor da universidade e a própria casa } \\
\text { dos estudantes. }\end{array}$ \\
\hline
\end{tabular}


Continuacão

\begin{tabular}{|c|c|c|c|c|}
\hline Autoria e local do estudo & $\begin{array}{c}\text { Características da } \\
\text { amostra } \\
\end{array}$ & $\begin{array}{c}\begin{array}{c}\text { Objetivo e tipo } \\
\text { do estudo }\end{array} \\
\end{array}$ & $\begin{array}{c}\text { Método de análise do consumo/hábito } \\
\text { alimentar }\end{array}$ & $\begin{array}{c}\begin{array}{c}\text { Resultados } \\
\text { principais }\end{array} \\
\end{array}$ \\
\hline $\begin{array}{l}\text { LEIBOVICH [31] } \\
\text { Brasilia - DF }\end{array}$ & $\begin{array}{l}173 \text { alunos divididos entre } \\
\text { grupo caso (alunos que } \\
\text { participavam de programas } \\
\text { assistenciais da universidade) e } \\
\text { grupo controle (estudantes } \\
\text { não inseridos nos programas). } \\
\text { Totalizando } 76 \text { mulheres e } 97 \\
\text { homens. }\end{array}$ & $\begin{array}{l}\text { Analisar o consumo de } \\
\text { alimentos e estado nutricional } \\
\text { dos estudantes que participavam } \\
\text { do Programa de Assistência } \\
\text { Estudantil da Universidade de } \\
\text { Brasilia e que frequentavam o } \\
\text { restaurante universitário. Estudo } \\
\text { tipo caso-controle. }\end{array}$ & 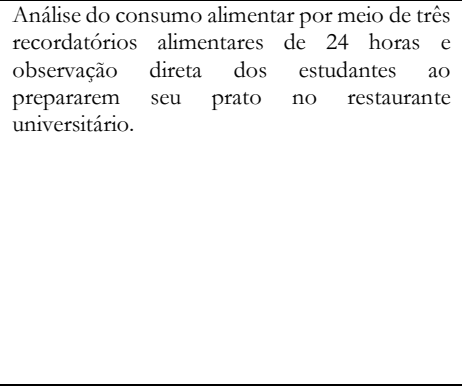 & $\begin{array}{l}\text { - a avaliação da composição física por bioimpedância mostrou que } 45,2 \% \text { das estudantes } \\
\text { do grupo "caso" apresentaram percentual de gordura corporal alto, embora a maioria } \\
\text { destas apresentassem peso normal. Já as estudantes do grupo "controle" apresentaram } \\
\text { um menor índice de inadequação do parâmetro; } \\
\text { - quanto aos estudantes do sexo masculino, o exame de bioimpedância detectou que a } \\
\text { maioria dos inseridos no grupo "casos" apresentou boa composição corporal. Já quanto } \\
\text { aos alunos do grupo "controle", } 40 \% \text { exibiu elevada porcentagem de gordura; } \\
\text { - os dois grupos apresentaram elevado consumo de sódio, extrapolando as } \\
\text { recomendações, e colesterol; } \\
\text { - quanto as frutas e hortaliças, embora as primeiras possuíssem um maior consumo entre } \\
\text { os homens, nos dois primeiros dias da pesquisa nenhum grupo consumiu as quantidades } \\
\text { recomendadas para estes alimentos; } \\
\text { - não foram encontradas diferenças significativas no padrão de consumo alimentar entre } \\
\text { os grupos. }\end{array}$ \\
\hline $\begin{array}{l}\text { ROSSETTI }[32] \\
\text { Piracicaba - SP }\end{array}$ & $\begin{array}{l}113 \text { acadêmicos da Escola } \\
\text { Superior de Agricultura "Luiz } \\
\text { de Queiroz" ( } 77 \text { mulheres e } 36 \\
\text { homens), embora apenas } 96 \\
\text { tenha participado da avaliação } \\
\text { do consumo alimentar. }\end{array}$ & $\begin{array}{l}\text { Analisar os hábitos alimentares, } \\
\text { o estado nutricional e a prática } \\
\text { de atividade física pelos alunos. } \\
\text { Estudo transversal seguido por } \\
\text { estudo qualitativo. }\end{array}$ & $\begin{array}{l}\text { Dois recordatórios alimentares de } 24 \text { horas e } \\
\text { um questionário validado com o intuito de } \\
\text { identificar os hábitos alimentares e estilos de } \\
\text { vida. Os alimentos consumidos foram } \\
\text { classificados em alimentos in } \\
\text { naturalminimamente processados, processados } \\
\text { e ultraprocessados. }\end{array}$ & $\begin{array}{l}\text { - apenas } 32,7 \% \text { dos universitários praticavam algum tipo de atividade física; } \\
\text { - cerca de } 17,7 \% \text { dos estudantes apresentaram IMC maiores que } 25,0 \mathrm{~kg} / \mathrm{m}^{2} \text {, sendo que } \\
\text { uma maior prevalência do problema foi relatada entre a população masculina; } \\
\text { - entre os estudantes do sexo masculino, os valores ingeridos de lipídeos, proteínas, } \\
\text { colesterol, ácidos graxos saturados e poli-insaturados apresentaram-se acima do } \\
\text { recomendado, sendo que o consumo de alimentos ultraprocessados foi apontado, pela } \\
\text { autora, por grande participação no valor energético total da dieta, constituindo na } \\
\text { principal fonte de ácidos graxos saturados; } \\
\text { - já entre as estudantes, a ingestão de fibra e ácidos graxos poli-insaturados foi baixa, } \\
\text { enquanto que o consumo de proteínas e ácidos graxos saturados esteve acima das } \\
\text { recomendações; } \\
\text { - o consumo de sódio apresentou-se elevado para ambos sexos. }\end{array}$ \\
\hline $\begin{array}{l}\text { TANTON et al. } \\
\text { Inglaterra }\end{array}$ & $\begin{array}{l}345 \text { alunos de graduação, de } \\
\text { uma universidade britânica. } \\
228 \text { mulheres e } 117 \text { homens. }\end{array}$ & 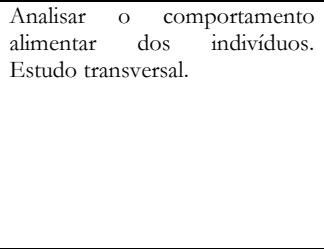 & $\begin{array}{l}\text { Utilização do questionário "Comportamento } \\
\text { alimentar dos estudantes" com questões } \\
\text { referentes às porções de alimentos ingeridas } \\
\text { durante os sete dias anteriores a aplicação do } \\
\text { instrumento. O consumo de frutas e hortaliças } \\
\text { foi comparado aos parâmetros britânicos. }\end{array}$ & $\begin{array}{l}\text { - apenas } 18,6 \% \text { dos alunos apresentaram comportamento alimentar favorável (baixo } \\
\text { consumo de fast-foods, médio consumo de snacks foods e elevado consumo de frutas e } \\
\text { vegetais); } \\
\text { - } 31,6 \% \text { dos universitários apresentaram comportamento alimentar "de risco", } \\
\text { caracterizado pelo baixo consumo de frutas e hortaliças e elevado consumo de fast-fods s } \\
\text { e snacks, ou comportamento alimentar misto (alto consumo de fast-foods e snacks e } \\
\text { consumo moderado de frutas e hortaliças); } \\
\text { - alunos que não moravam na mesma casa que os pais, no geral, consumiram menos } \\
\text { frutas e hortaliças em relação àqueles que moravam com o responsável. }\end{array}$ \\
\hline $\begin{array}{l}\text { PEREZ et al. }{ }^{[34]} \\
\text { Rio de Janeiro - RJ }\end{array}$ & $\begin{array}{l}1336 \text { alunos, } \quad \text { o que } \\
\text { correspondia a } 88,6 \% \text { dos } \\
\text { ingressantes da Universidade } \\
\text { Federal do Rio de Janeiro. } \\
582 \text { homens e } 754 \text { mulheres }\end{array}$ & 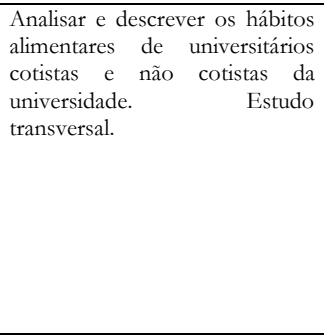 & $\begin{array}{l}\text { Questionário validado contendo perguntas a } \\
\text { respeito do consumo de alimentos } \\
\text { (classificados em marcadores de uma } \\
\text { alimentação saudável e não saudável) e rotinas } \\
\text { alimentares. A classificação dos alimentos foi } \\
\text { baseada nas recomendações nutricionais e } \\
\text { estudos que os associam ao risco de DCNT. }\end{array}$ & $\begin{array}{l}\text { - alimentos marcadores de uma alimentação saudável como feijão, hortaliças e frutas } \\
\text { apresentaram baixa frequência de consumo diário entre os alunos, enquanto as bebidas } \\
\text { açucaradas, guloseimas, biscoitos e salgadinhos foram consumidos, diariamente, por } \\
46,2 \%, 24,9 \% \text { e } 17,9 \% \text { dos estudantes, respectivamente; } \\
\text { - em relação aos hábitos alimentares dos cotistas comparado aos não cotistas, entre os } \\
\text { primeiros, o consumo regular de feijão, biscoitos e salgadinhos foi relatado por um maior } \\
\text { número de alunos, enquanto que entre os não cotistas, houve um maior número de } \\
\text { estudantes consumindo regularmente hortaliças cruas, frutas e bebidas açucaradas; } \\
\text { - indivíduos provenientes de familias com maior poder aquisitivo consumiam mais frutas } \\
\text { e hortaliças e menos feijão; } \\
\text { - a alimentação dos cotistas e não cotistas foram semelhantes e marcadas por práticas } \\
\text { desfavoráveis à saúde. }\end{array}$ \\
\hline
\end{tabular}


Continuacão

\begin{tabular}{|c|c|c|c|c|}
\hline Autoria e local do estudo & $\begin{array}{l}\text { Características da } \\
\text { amostra }\end{array}$ & $\begin{array}{l}\text { Objetivo e tipo } \\
\text { do estudo }\end{array}$ & $\begin{array}{l}\text { Método de análise do consumo/hábito } \\
\text { alimentar }\end{array}$ & $\begin{array}{c}\text { Resultados } \\
\text { principais }\end{array}$ \\
\hline $\begin{array}{l}\text { TASSITANO et al. }{ }^{[35]} \\
\text { Pernambuco }\end{array}$ & $\begin{array}{l}717 \text { universitários da } \\
\text { Universidade Federal Rural de } \\
\text { Pernambuco. } \\
401 \text { alunas e } 316 \text { alunos. }\end{array}$ & $\begin{array}{l}\text { Evidenciar elementos, como } \\
\text { interferentes no consumo de } \\
\text { frutas, legumes e hortaliças. } \\
\text { Estudo transversal. }\end{array}$ & $\begin{array}{l}\text { Questionário de frequência alimentar } \\
\text { constitúdo por } 21 \text { frutas e vegetais } \\
\text { amplamente consumidos no Brasil, no qual os } \\
\text { alunos deveriam informar o número de } \\
\text { porções ingeridas por dia. }\end{array}$ & $\begin{array}{l}\text { - o consumo médio de frutas e hortaliças encontrado entre os acadêmicos foi bastante } \\
\text { baixo, cerca de apenas } 2 \text { porçõos ao dia, não variando significativamente entre os sexos; } \\
\text { - apesar disso, o consumo destes alimentos entre os homens foi superior quando } \\
\text { comparado às mulheres; } \\
\text { - os universitários do sexo masculino também destinavam mais tempo para a prática de } \\
\text { atividade física. }\end{array}$ \\
\hline $\begin{array}{l}\text { CARDOSO } \\
\text { Piracicaba-SP }\end{array}$ & $\begin{array}{l}114 \text { estudantes da ESALQ } \\
\text { durante a primeira fase ( } 78 \\
\text { mulheres e } 36 \text { homens) e } 96 \\
\text { durante a segunda fase ( } 71 \\
\text { mulheres e } 25 \text { homens). }\end{array}$ & $\begin{array}{l}\text { Identificar mudanças no } \\
\text { consumo alimentar, nível de } \\
\text { atividade física e estado } \\
\text { nutricional dos alunos durante } \\
\text { um período de } 8 \text { meses. Estudo } \\
\text { de Coorte (longitudinal). }\end{array}$ & $\begin{array}{l}\text { Questionário validado aplicado com o intuito } \\
\text { de identificar os hábitos alimentares e atividade } \\
\text { física dos alunos. O consumo alimentar foi } \\
\text { avaliado através de } 2 \text { recordatórios alimentares } \\
\text { de } 24 \text { horas. Os alimentos consumidos foram } \\
\text { classificados em in natura/minimamente } \\
\text { processados, processados e ultraprocessados. }\end{array}$ & $\begin{array}{l}\text { - durante os oito meses que transcorreram entre a primeira da segunda fase do estudo } \\
\text { houve aumento de peso entre os estudantes, embora esse aumento não tivesse sido } \\
\text { significativo; } \\
\text { - na segunda fase } 14,58 \% \text { dos acadêmicos eram portadores de sobrepeso, e } 3,13 \% \text { eram } \\
\text { obesos; } \\
\text { - quanto ao consumo alimentar, as quantidades de proteínas e sódio ingeridas } \\
\text { permaneceram elevadas na segunda fase do estudo, embora o consumo do último tivesse } \\
\text { sido reduzido. Quanto aos lipídeos, a ingestão de quantidades adequadas manteve-se } \\
\text { entre os acadêmicos, porém entre as estudantes, o consumo deste nutriente se elevou; } \\
\text { - em relação a ingestão das fibras, entre as alunas, o consumo permaneceu baixo, porém } \\
\text { entre os homens, houve um aumento de modo que atingiu-se a quantidade mínima } \\
\text { recomendada } \\
\text { - quanto a prática de atividade física, uma redução do número de praticantes foi } \\
\text { observada na segunda fase especialmente entre as universitárias; } \\
\text { - a ingestão de carotenoides, compostos medidores de uma alimentação saudável por } \\
\text { estarem presentes em frutas, hortaliças e derivados, também apresentou-se abaixo do } \\
\text { recomendado; } \\
\text { - na } 2^{2} \text { fase da pesquisa, o número de alunos que denotaram uma queda na qualidade da } \\
\text { alimentação, após inserção na universidade, aumentou. }\end{array}$ \\
\hline
\end{tabular}


Conforme pode ser observado, entre os universitários predominaram hábitos alimentares inadequados. As proporções de indivíduos portadores de sobrepeso e obesidade também são, de modo geral, consideradas elevadas. Essa situação assume maior importância quando se considera a pouca idade destes estudantes, que normalmente não atingiram os 30 anos. A ocorrência de sobrepeso/obesidade e sua inerente relação com os maus hábitos alimentares e sedentarismo das populações não são fenômenos restritos ao Brasil ou a algumas de suas regiões, mas vêm sendo apresentados e discutidos como uma tendência mundial afetando países desenvolvidos e em desenvolvimento, como mostraram os estudos conduzidos por Peltzer et al. [1], Huang et al. [13], Brunt et al. [17], Ansari, Stock e Mikolajczyk [22], Burriel et al. [25] e Tanton et al. [33].

Ao comparar os resultados de estudos internacionais, muitas semelhanças podem ser identificadas, como é o caso da substancial redução no consumo de frutas e hortaliças, ocasionando menor aporte dietético de fibras, a prática insuficiente de atividade física e a elevada ingestão de bebidas alcóolicas, doces, alimentos gordurosos, carnes, fast foods, alimentos processados e ultraprocessados, que contribuem, notavelmente, para que seja expressivo o número de acadêmicos portadores de sobrepeso e obesidade $[1,13,17,22,25,33]$.

No Brasil, a presença de comportamentos alimentares de risco, semelhantes aos demonstrados nas pesquisas internacionais também foram identificados em diversos estudos que amostraram universitários oriundos de distintos estados.

No Acre (Região Norte) foi apontado o baixo consumo de frutas e hortaliças pelos estudantes, bem como sua relação com a classe social, nível de atividade física e consumo de fast foods [24].

$\mathrm{Na}$ região Nordeste, foi constatada a prevalência expressiva de sobrepeso e de obesidade entre os acadêmicos, condicionada pela adoção de hábitos alimentares inadequados, (densidade de energia, alta ingestão de colesterol e gordura saturada) $[16,19,20,35]$.

No Centro-Oeste, foram identificados comportamentos como omissão de refeições, ingestão considerável de alimentos pouco nutritivos (massas, fast foods, bolachas, salgados), sedentarismo, consumo significante de bebidas alcóolicas e presença de sobrepeso/obesidade ${ }^{[14,18,31]}$.

Os estudos selecionados realizados na região Sudeste englobaram tanto universidades públicas, situadas nos estados do Rio de Janeiro, São Paulo e Minas Gerais, quanto instituições privadas localizadas nos municípios de Guarulhos e Mogi Guaçu, (ambos pertencentes ao estado de São Paulo) [11,15,21,23,28,30,32,34,36].

Nas faculdades particulares foi observada inadequação do consumo alimentar por parte dos estudantes que já estavam concluindo o curso de graduação em nutrição na cidade de Guarulhos, embora muitos tenham relatado maior adesão ao café da manhã e melhora nos hábitos alimentares ou declarado interesse em modificar estes aspectos; já em Mogi Guaçu identificou-se, entre os acadêmicos, elevada ingestão de alimentos de baixa qualidade nutricional adquiridos, normalmente, da própria cantina universitária [21,28]. Este último estudo contemplou, também, variáveis como contingente de alunos que exerciam alguma atividade remunerada e estudavam, sendo que $85 \%$ dos estudantes abordados possuíam este perfil, o que pode dificultar a manutenção de uma alimentação saudável, em virtude do menor tempo destinado ao preparo e consumo das refeições, fazendo com que muitos prefiram adquirir alimentos práticos e, usualmente, de baixa qualidade nutricional, omitam algumas refeições ou as realizem "fora de hora", fatores que podem contribuir para o aumento no peso [28].

Em relação às universidades públicas que integram essa mesma região, Cardoso ${ }^{[36]}$ ao analisar o comportamento de alunos em um campus da Universidade de São Paulo, situado no interior do estado, identificou que apenas 5,31\% dos acadêmicos realizavam alguma atividade remunerada, já que muitos estudavam em período integral. A renda média mensal encontrada entre estes indivíduos variou entre $\mathrm{R} \$ 5.037,25$ e $\mathrm{R} \$ 6.293,65$, sendo classificada como elevada para os padrões nacionais e superior àquelas obtidas por meio de estudos realizados com alunos de faculdades privadas e de outras universidades públicas [36. Apesar disso, foram também observados, entre esta população, maus hábitos e escolhas alimentares, considerável número de portadores de sobrepeso e obesidade, elevados consumo de alimentos processados, ultraprocessados e bebidas alcóolicas e baixo nível de atividade física, embora estes indivíduos, por possuírem maior nível de informação e recursos disponíveis, tivessem condições de destinar parcelas 
desses recursos para a aquisição de alimentos mais saudáveis e à prática regular de exercício. Outras pesquisas realizadas em universidades públicas do Sudeste evidenciaram, além dos fatores anteriormente citados, omissões de refeições ou realização de refeições incompletas pelos estudantes [11,15,23,30,32,34].

$\mathrm{Na}$ região Sul predominou a baixa ingestão de alimentos in natura (frutas e hortaliças), consumo relevante de álcool, doces, embutidos, frituras e salgadinhos e omissão de refeições [27,28,30].

Estes dados corroboram com a questão exposta inicialmente, demonstrando ser predominante, a adoção de práticas alimentares inadequadas e de estilos de vida insalubres por grande parte destes jovens adultos.

Greaney et al. [9] apontaram que o maior ganho de peso ocorria durante o início da fase adulta, ou seja aos 20 anos de idade e que, se caso esse ganho fosse em excesso, poderia aumentar a probabilidade de um indivíduo ter sobrepeso ou vir a tornar-se obeso em períodos posteriores da vida adulta.

A última POF realizada entre os anos de 2008 e 2009 mostrou que cerca de $45 \%$ do total de calorias presentes na dieta da população brasileira provinha de cereais, leguminosas, raízes e tubérculos [37]. Alimentos com alto valor energético, como aqueles provenientes de óleos e gorduras vegetais, gorduras animais, açúcares (sacarose), refrigerantes e bebidas alcóolicas contribuíram com $28 \%$ do aporte energético da dieta, enquanto que as carnes, leite e derivados e ovos (alimentos de origem animal) correspondiam a 19\% [37]. As frutas e hortaliças, entretanto, apresentaram consumo baixíssimo pelos brasileiros, representando, apenas, 2,8\% das calorias ingeridas, quantidade equivalente a apenas um quarto das recomendações dietéticas para estes grupos de alimentos [37].

Os alimentos que, nos últimos anos, apresentaram expressiva elevação do consumo pelo brasileiro foram o pão francês, os biscoitos, os queijos, outros derivados de leite, as carnes bovinas, os embutidos, as frutas e os sucos de frutas, os refrigerantes, as bebidas alcóolicas e as refeições prontas/industrializadas [37,38]. Já o arroz, o feijão, a farinha de trigo e mandioca, o leite e o açúcar tiveram participação reduzida no valor energético da dieta, evidenciando um quadro de crescente redução no consumo de alimentos básicos e constante aumento na ingestão de produtos processados e ultraprocessados o que ilustra uma considerável diminuição da qualidade da alimentação $[37,38]$.

Louzada et al. ${ }^{[39]}$ apontaram que em países de renda média, como é o caso do Brasil, realmente existe uma tendência de aumento no consumo de produtos ultraprocessados por diversos estratos etários e sociodemográficos da população, impulsionados pelo marketing, praticidade e sabores oferecidos por estes produtos. Além disso, alimentos processados e ultraprocessados possuem menor custo relativo quando comparados às outras categorias, além de preços mais estáveis que os produtos de origem vegetal, como as frutas e hortaliças, favorecendo seu consumo por, principalmente, indivíduos com menor poder aquisitivo [32].

Estudos realizados com base na POF 20082009 demonstraram que cerca de $21,5 \%$ do consumo energético diário do brasileiro era proveniente de alimentos ultraprocessados, com destaque principal para tortas e bolachas doces, fast foods, refrigerantes e refrescos, pães (de forma, hambúrguer e cachorro quente), guloseimas em geral, biscoitos salgados, salgadinhos (tipo chips), embutidos, bebidas à base de leite adoçadas e refeições prontas [39]. Estes alimentos, de modo geral, apresentam maiores teores de açúcares livres, gorduras (saturadas e trans) e conteúdo energético e menores porções de proteínas e fibras quando comparados aos alimentos in natura ou minimamente processados [39].

O elevado consumo destes produtos, ricos em açúcares, está relacionado ao aumento da densidade energética e do contingente de carboidratos simples na dieta, o que pode aumentar as chances de uma pessoa apresentar ganho excessivo de peso ou tornar-se obesa, além de elevar a incidência de carie dental [39]. As gorduras, em especial as saturadas e trans estão relacionadas às doenças cardiovasculares, enquanto que a baixa ingestão de fibras vem sendo associadas a fenômenos como obesidade, diabetes e diversos tipos de câncer [39]. Outras DCNT, como a Síndrome Metabólica em adolescentes, também vêm sendo associadas, em pesquisas recentes, ao consumo excessivo de ultraprocessados [39]. Estudos apontam, assim, ser, o estímulo à redução do consumo destes alimentos, uma estratégia fundamental para a promoção de saúde e de uma alimentação equilibrada, conforme 
preconizado pelo Guia Alimentar para a População Brasileira, publicado no ano de 2014 [39].

Fernandes et al. [40] por meio de estudo transversal, realizado com 261 graduandos do primeiro ano de cursos da Universidade de Rhode Island, nos Estados Unidos, também demostraram a importância que a adoção de hábitos alimentares saudáveis exerce na prevenção de doenças coronárias entre os universitários, avaliando, nos indivíduos, fatores como IMC, indicadores de atividade física, pressão arterial, ingestão alimentar e níveis séricos de colesterol total, colesterol HDL e LDL, triglicérides e glicose. Como resultados, destacaram que o exagerado consumo de carboidratos, gordura, açúcares e sacarina estiveram associados a diminuição dos níveis séricos de HDL [40]. Já valores de IMC elevados, além de estarem correlacionados à diminuição dos níveis sanguíneos do biomarcador em questão, também encontraram-se relacionados ao aumento dos níveis de glicose [40]. $\mathrm{O}$ estudo identificou, ainda, que a excessiva ingestão de álcool promoveu elevação de $9,9 \%$ no risco dos indivíduos apresentarem aumento dos níveis de triglicérides sanguíneos e que a adoção de hábitos de vida saudáveis contribuiu significativamente para a melhora dos níveis de HDL e redução de parâmetros como circunferência abdominal e níveis séricos de triglicérides e glicose ${ }^{[40]}$.

Claro et al. ${ }^{[41]}$ analisando dados da Pesquisa Nacional de Saúde (PNS) realizada em 2013 identificaram que o consumo de alimentos considerados fatores de risco para o desenvolvimento de doenças crônicas pela população é elevado. Os alimentos que mereceram destaque são aqueles ricos em gorduras saturadas como as carnes com excesso de gordura e o leite integral [41]. Já aqueles com altos teores de açúcar, como os refrigerantes, sucos industrializados e doces, apresentaram menor consumo entre a população quando comparados ao primeiro grupo, apesar disso é importante salientar que o consumo de açúcares pela população excede em $50 \%$ as quantidades preconizadas pela Organização Mundial de Saúde [41]. Outro fator identificado nesta pesquisa e que demanda atenção refere-se ao fato de que a ingestão destes alimentos foi mais frequente entre os homens, principalmente entre aqueles com menor escolaridade $\mathrm{e}$ idade [41].

Dados do Vigitel (Vigilância de Fatores de Risco e Proteção para Doenças Crônicas por Inquérito Telefônico) realizado em 2014 mostraram que, entre a população brasileira com idade entre 19 a 24 anos, o consumo regular de frutas e hortaliças (no mínimo cinco vezes na semana) foi verificado para apenas 34\% da população ${ }^{[42]}$. Já a ingestão de no mínimo cinco porções diárias destes alimentos foi declarada por apenas $22,9 \%$ destes jovens ${ }^{[42]}$. A pesquisa apontou, também que o consumo destes alimentos foi maior entre as mulheres e tendeu a se elevar em função dos anos de estudo e da idade para ambos sexos [42]. Em relação ao feijão, este teve o consumo considerado regular por $67,1 \%$ dos indivíduos desta mesma população, tendendo a diminuir em função do aumento da idade e nível de escolaridade [42].

A ingestão de carnes com excesso de gorduras foi considerada habitual por $35,2 \%$ da população adulta jovem, sendo mais expressiva entre indivíduos do sexo masculino, o mesmo aconteceu para o hábito de consumir refrigerantes regularmente, sendo este apontado por $30 \%$ dos adultos com idades entre 19 e 24 anos ${ }^{[42]}$. Já o hábito de ingerir doces por no mínimo cinco dias da semana esteve presente em 31,1\% dos jovens, apresentando-se mais frequente entre as mulheres [42]. A substituição de refeições por sanduíches, pizzas e salgados foi usual para 16\% destes jovens, apresentando-se, também, mais regular entre a população feminina [42]. Em relação a percepção do consumo de sódio, este foi classificado como sendo elevado ou muito elevado para, respectivamente, 25,3\% dos jovens do sexo masculino e $28,4 \%$ das mulheres com no máximo 24 anos ${ }^{[42] .}$

Alimentos in natura ou minimamente processados, apesar de serem considerados alimentos nutricionalmente ricos, devido à presença de compostos bioativos, fibras, vitaminas e minerais, auxiliando no bom funcionamento do organismo e na prevenção de doenças, têm seu consumo cada vez mais restrito e reduzido nos últimos anos [37,38], fato que pode ser observado nos universitários de diversas regiões.

De acordo com os estudos realizados por Jaime et al. [43] utilizando como base dados disponibilizados pela PNS - 2013, apenas 37,3\% da população brasileira ingeria pelo menos cinco porções diárias de frutas, atendendo aos valores preconizados pela OMS, já o feijão era consumido regularmente por $71,9 \%$ dos brasileiros. Ao analisar o consumo destes alimentos por regiões, identificou-se que a ingestão de frutas e hortaliças foi mais prevalente nas regiões Sudeste e Centro-Oeste, indicando que, no Brasil, o 
consumo alimentar é fortemente influenciado por aspectos sociodemográficos ${ }^{[43]}$.

As hortaliças e as frutas, principalmente, por serem alimentos com maior custo, são consumidas majoritariamente por pessoas com maior nível de instrução, residentes nas áreas urbanas e com maior renda média; já o feijão, por apresentar baixo custo e ser um alimento tradicional, teve seu consumo mais expressivo entre os indivíduos com menor escolaridade e habitantes de zonas rurais [43]. Dados da POF 20082009 evidenciaram que pessoas com menor renda ingerem, em média, apenas 156,5 gramas de frutas e hortaliças ao dia, frente aos 293,5 gramas ingeridos diariamente pelos indivíduos com maior poder aquisitivo [36], concordando com os dados obtidos na pesquisa envolvendo universitários (cotistas e não cotistas), realizada por Perez et al. [34], que mostrou que estudantes com maiores rendimentos consumiam mais frutas e hortaliças e menos feijão quando comparados àqueles provenientes de famílias com menor renda.

É interessante citar, também, a influência que o Restaurante Universitário, as cantinas localizadas dentro da faculdade, bem como os restaurantes nas proximidades da área de estudo exercem na alimentação dos estudantes. Enquanto o Restaurante Universitário favorece práticas de promoção à saúde, por apresentar baixo preço (em algumas universidade apenas $\mathrm{R} \$ 1,90)$, sendo apontado, por alguns alunos como um "facilitador de refeições" e contribuindo para o acesso de todos os matriculados a uma maior variabilidade de alimentos, principalmente os de origem vegetais e a uma alimentação balanceada nutricionalmente [32,36]; as cantinas e lanchonetes, situadas no interior da universidade, estão muitas vezes associadas a oferta e aquisição de alimentos processados e ultraprocessados pelos estudantes, principalmente durante o período de aula [28], dificultando a manutenção de hábitos de vida saudáveis.

\section{Fatores determinantes do comportamento alimentar}

Segundo Assis e Nahas [44] e Pedraza [45] o comportamento alimentar de um indivíduo tem início na infância, a partir do momento em que a família oferece alimentos típicos de sua cultura para o bebê. Os hábitos alimentares a serem formados sofrem, desse modo, a influência de fatores como preço, crenças e valores em relação aos alimentos, modo de preparo, geografia local, religião, propaganda, industrialização, entre outras influências sociais, sendo, assim, caracterizados como fruto da interação dos elementos culturais, psicológicos, sociais, econômicos e antropológicos ${ }^{[4,45] \text {. }}$

Maciel et al. [23] afirmam ainda, que as escolhas alimentares da população são também influenciadas por fatores como renda familiar, nível de urbanização do local onde habitam, grau de escolaridade, grau de acesso a alimentos diversificados, faixa etária do indivíduo e características inerentes ao próprio alimento, como, por exemplo, suas qualidades sensoriais e tradição ao consumo.

Pode-se, portanto, inferir que o comportamento alimentar é caracterizado como um agregado de ações referentes ao alimento, que se inicia a partir da escolha do alimento a ser consumido, seu horário de consumo, sua disponibilidade e seu modo de preparo e finaliza com a sua digestão [21].

Para Dutra et al. [46], a obesidade é hoje considerada uma epidemia mundial, sendo vista como uma consequência da globalização e de seus fatores adjuntos como a industrialização, o desenvolvimento econômico e a urbanização, que acabam promovendo mudanças nem sempre tão boas nos hábitos alimentares das populações.

Embora seja considerada uma doença com múltiplos fatores etiológicos, o fator ambiental é crucial para o seu desenvolvimento, já que, na maioria das vezes, contribui para que haja uma elevação no consumo de alimentos industrializados, que aumentam, em demasia, a ingestão energética individual, e uma diminuição no gasto energético diário, estimulada pelo desenvolvimento da tecnologia e pela facilidade de acesso aos automóveis [46].

Tassitano et al. [35] e Perez et al. [34] consideram o ambiente universitário, bem como o período de ingresso em uma universidade, fatores que dificultam a manutenção de hábitos de vida saudáveis, pois é geralmente durante este período que os estudantes tornam-se responsáveis pela sua moradia, finanças, administração do tempo e sua alimentação.

Borges e Lima Filho ${ }^{[14]}$ concluíram que a escolha dos alimentos entre os alunos de uma universidade era extensivamente influenciada por 
fatores como tempo, recursos financeiros, lugar, variedade e qualidade, e que a inserção em uma faculdade promoveu alterações nos hábitos alimentares destes estudantes.

A incorreta administração do tempo destinado aos estudos e trabalhos oriundos da vida universitária, bem como dispêndio de muitas horas para a manutenção de uma vida social "ativa", ambicionada por muitos durante essa fase da vida, muitas vezes faz com que os alunos omitam alguma refeição durante o dia ou as substituam por lanches rápidos e pouco nutritivos, ricos em gorduras e com alto valor energético [12]. Estes comportamentos estão associados ao ganho de peso e ao aumento do risco de desenvolvimento de DCNT em períodos futuros [33].

Greaney et al. ${ }^{[9]}$ mostraram, em seus estudos, que a baixa ingestão de frutas e hortaliças e o elevado consumo de gordura saturada, açúcares, alimentos hipercalóricos e bebidas alcoólicas era bastante frequente entre os jovens universitários norteamericanos, que citaram a falta de disciplina, a vida social agitada, o tempo reduzido, o fácil acesso aos alimentos de baixa qualidade nutricional e a tentação oferecida ao consumo destes alimentos, geralmente mais saborosos, como principais fatores que dificultavam a manutenção de hábitos de vida saudáveis.

Verhoeven [47], por meio de estudo transversal, que visou identificar quais fatores são determinantes do consumo de frutas, hortaliças e gordura por estudantes em uma universidade belga, mostrou que o consumo de frutas e vegetais é baixo, variando entre 146 a 178,8 $\mathrm{g} / \mathrm{dia}$, enquanto que o consumo de gordura esteve em torno de 26,6 e 56,2 g/dia, atendendo aos valores preconizados, o que pode ser justificado pelo fato de não haver restaurantes fast foods nos arredores do campus. Os principais determinantes do consumo de frutas e hortaliças, apontados pela pesquisa, foram: o sexo (mulheres consumiam maiores quantidades), o fato do estudante já estar realizando algum tipo de dieta, ser vegetariano, ter maior autocontrole, preferir consumir alimentos mais saudáveis e a existência de modelos sociais; já o tempo restrito, a ausência de disciplina, a falta de interesse e conhecimento a respeito dos alimentos, a tentação oferecida ao consumo de outros alimentos "mais saborosos" e o fato de não apreciar frutas e hortaliças foram apontados como principais barreiras ao consumo destes alimentos. Em relação a ingestão de gorduras, o fato de estar realizando uma dieta, ser mulher, ter maior autocontrole, bem como o impacto da imagem corporal foram identificados como principais barreiras ao consumo, já a falta de interesse, falta de suporte social e o fato de alimentos pobres em gorduras serem considerados como "pouco saborosos" constituíram nos principais fatores que contribuíram para a ingestão de gordura entre os universitários.

Deliens et al. ${ }^{[10]}$ buscaram identificar, por meio de discussões envolvendo grupos focais, quais fatores intervinham nas escolhas alimentares e quais promoviam o consumo de bebidas alcóolicas entre universitários belgas. De acordo com os resultados, fatores como autodisciplina, valores, normas e crenças, estresse gerado pelos estudos e semanas de provas, imagem corporal, conhecimentos a respeito de alimentação e nutrição, falta de tempo e necessidade de praticidade e conveniência na alimentação, metabolismo do indivíduo, necessidade de energia, ritmo de vida diário e padrão alimentar desenvolvido durante a infância foram apontados como principais interferentes, no que tange o plano individual, no comportamento alimentar destes estudantes. Já em relação aos fatores provenientes dos ambientes sociais, da comunidade universitária e do macro-ambiente (cultural, político e legal), foram citados o controle exercido pelos pais, a educação e os hábitos de vida familiar, o apoio social fornecido pela família e pelos amigos, a pressão do parceiro ou parceira, o nível de acesso aos alimentos saudáveis, o custo destes alimentos, a presença de máquina de doces em todo o campus universitário, o estilo de vida universitário e os padrões socioculturais da nação, como sendo as principais influências nas escolhas e comportamento alimentares destes jovens adultos. Como principais justificativas para a promoção do consumo de álcool entre os universitários, os estudantes citaram, ainda, a maior independência, o baixo controle exercido pelos pais nessa fase da vida, a influência dos amigos e da "vida social" universitária, o baixo policiamento, a inefetividade das leis de fiscalização do país e o fato do álcool ser uma droga lícita, ou seja, com consumo permitido por lei e completamente aceito pela sociedade. Os autores afirmam, ainda, que o consumo de bebidas alcóolicas contribui significativamente para o aumento do aporte energético da dieta de universitários, auxiliando, também, na promoção do ganho de peso durante essa etapa.

Em relação ao nível de atividade física, o mesmo diminui quando os adolescentes ingressam em uma universidade, sendo que a falta de tempo, dinheiro, 
local para prática de exercício físico, bem como a falta de interesse para a realização de atividade física são considerados os principais fatores que justificam essa redução durante o período de graduação ${ }^{[48]}$.

\section{CONSIDERAÇÕES FINAIS}

A alimentação dos universitários, apresenta-se, de modo geral, bastante inadequada, em razão da elevada ingestão de alimentos processados e a base de açúcar e do baixo consumo de alimentos marcadores de uma alimentação saudável como as frutas, hortaliças e grãos, ricos em compostos bioativos, capazes de auxiliar na prevenção das doenças crônicas. Desse modo, os jovens acabam ingerindo uma elevada quantidade de sódio, lipídeos e colesterol e apresentando um baixo consumo de nutrientes essenciais como as fibras, vitaminas, minerais e ácidos graxos poli-insaturados.

Além disso, atualmente ocorre, também, uma elevação no número de estudantes que apresentam sobrepeso e obesidade, ocasionados, entre outros condicionantes, pela diminuição da prática de atividade física, aumento dos níveis de sedentarismo e crescente consumo de bebidas alcóolicas, condição amplamente vivenciada pelos universitários.

Como os estudos mostraram, esse é um fenômeno que não é exclusivo do Brasil, mas que afeta diversos países espalhados por distintos continentes.

Desse modo, ressalta-se a importância de programas dentro das próprias universidades que visem a promoção da saúde entre seus estudantes, estimulando-os quanto a prática de atividade física e a adoção de uma alimentação saudável e balanceada, por meio da adequação dos cardápios dos restaurantes universitários, por exemplo, já que estes são frequentados por muitos acadêmicos, e de acordos realizados com os proprietários das cantinas localizadas dentro das faculdades, com o intuito de reduzir a oferta dos alimentos processados e ultraprocessados e melhorar, de modo geral, a qualidade da comida comercializada nestes estabelecimentos.

Programas de saúde pública voltadas a este público específico e com enfoque nos hábitos desta população também são necessários, prevenindo, assim, o risco destes indivíduos serem acometidos por doenças crônicas em períodos posteriores e melhorando a qualidade de vida dos mesmos desde já.

\section{REFERÊNCIAS}

[1] Peltzer K, Pengpid S, Samuels TA, Ozcan NK, Mantilla C, Rahamefy $\mathrm{OH}$, et al. Prevalence of overweight/obesity and its associated factors among university students from 22 countries. Int. J. Environ. Res. Public Health. 2014;11:7425-7441.

[2] Instituto Brasileiro de Geografia e Estatística. Pesquisa de Orçamentos Familiares 2008-2009: antropometria e estado nutricional de crianças, adolescentes e adultos no Brasil. Rio de Janeiro; 2010.

[3] Rodriguez-Amaya DB, Kimura M, Amaya-Farfan J. Fontes brasileiras de carotenóides: tabela brasileira de composição de carotenóides em alimentos. Brasília: Ministério do Meio Ambiente, Secretaria de Biodiversidade e Floresta; 2008.

[4] Monteiro CA. Nutrition and health: the issue is not food, nor nutrients, so much as processing. Public Health Nutr. 2009;12:729-731.

[5] Eisenstein E. Adolescência: definições, conceitos e critérios. Adolesc. Saúde. 2005;2:6-7.

[6] Jacobson MS. Nutrição na adolescência. Anais Nestlé. 1998;55:24-33.

[7] Moreno-Goméz C, Romanguera-Bosch D, Tauler-Riera P, Bennasar-Veny M, Pericas-Beltran J, Martinez-Andreu S, et al. Clustering of lifestyle factors in Spanish university students: the relationships between smoking alcohol consumption, physical activity and diet quality. Public Health Nutr. 2012;15:2131-2139.

[8] Vieira VCR, Priore SE, Ribeiro SMR, Franceschini SCC, Almeida LP. Perfil socioeconômico, nutricional e de saúde de adolescentes recém-ingressos em uma universidade pública brasileira. Rev. Nutr. 2002;15:273-282.

[9] Greaney ML, Less FD, White AA, Dayton SF, Riebe D, Blissmer B, et al. College students' barriers and enablers for healthful weight management: a qualitative study. J. Nutr. Educ. Behav. 2009;41:281-286.

[10] Deliens T, Clarys P, Bourdeaudhuij I, Deforche B. Determinats of eating behavior in university students: a qualitative study using focus group discussion. BMC Public Health. 2014;14:1-12.

[11] Monteiro MRP, Andrade MLO, Zanirati VF, Silva RR. Hábito e consumo alimentar de estudantes do sexo feminino dos cursos de nutrição e enfermagem de uma universidade pública brasileira. Rev. APS. 2009; 12:271-277.

[12] Duarte FM, Almeida SDS, Martins KA. Alimentação fora do domicílio de universitários de alguns cursos da área da saúde de uma instituição privada. O Mundo da Saúde. 2013;37:288-298. 
[13] Huang T'TK, Harris KJ, Lee RE, Nazir N, Born W, Kaur H. Assessing overweight, obesity, diet and physical activity in college students. J. Am. Coll. Health. 2003;52:83-86.

[14] Borges C, Lima Filho DO. Hábitos alimentares dos estudantes universitários: um estudo qualitativo. In: Anais do VII SemeAd - Seminários em Administração; 10-11 ago 2004; São Paulo. São Paulo: FEA-USP; 2004.

[15] Alves HJ, Boog MCF. Comportamento alimentar em moradia estudantil: um espaço para a promoção de saúde. Rev. Saúde Pública. 2007;41:197-204.

[16] Franca C, Colares V. Estudo comparativo de condutas de saúde entre universitários no início e no final do curso. Rev. Saúde Pública. 2008;42:420-427.

[17] Brunt A, Rhee Y, Zhong L. Differences in dietary patterns among college students according to body mass index. J. Am. Coll. Health. 2008;56:629-634.

[18] Marcondelli P, Da Costa THM, Schimtz BAS. Nível de atividade física e hábitos alimentares de universitários do 3o ao 5o semestres da área da saúde. Rev. Nutr. 2008;21:39-47.

[19] Petribu MMV, Cabral PC, Arruda IKG. Estado Nutricional, consumo alimentar e risco cardiovascular: um estudo em universitários. Rev. Nutr. 2009;22:837-846.

[20] Feitosa EPS, Dantas CAO, Andrade-Wartha ERS, Marcellini OS, Mendes-Netto RS. Hábitos alimentares de estudantes de uma universidade pública no nordeste, Brasil. Alim. Nutr. 2010;21:225-230.

[21] Matias CT, Fiore EG. Mudanças no comportamento alimentar de estudantes do curso de nutrição em uma instituição particular de ensino superior. Nutrire. 2010;35:53-66.

[22] Ansari WE, Stock C, Mikolajczyk RT. Relationships between food consumption and living arrangements among university students in four European countries - a crosssectional study. Nutr. J. 2012;11:1-7.

[23] Maciel ES, Sonati JG, Modeneze DM, Vasconcelos JS, Vilarta R. Consumo alimentar, estado nutricional e nível de atividade física em comunidade universitária brasileira. Rev. Nutr. 2012;25:707-718.

[24] Ramalho AA, Dalamaria T, Souza OF. Consumo regular de frutas e hortaliças por estudantes universitários em Rio Branco, Acre, Brasil: prevalência e fatores associados. Cad. Saúde Pública. 2012;28:1405-1413.

[25] Burriel FC, Urrea RS, García CV, Tobarra MM, Meseguer MJG. Hábitos alimentarios y evaluación nutricional em uma población universitaria. Nutr. Hosp. 2013;28:438-446.
[26] Gasparotto GS, Gasparotto LPR, De Salles MR, De Campos W. Fatores de risco cardiovascular em universitários: comparação entre sexos, períodos de graduação e áreas de estudo. Medicina. 2013;46:154-163.

[27] Silva KM, Busnello MB. Hábitos alimentares em acadêmicos do curso de nutrição Ijuí: Universidade Regional do Noroeste do Estado do Rio Grande do Sul; 2013. Trabalho de conclusão de curso.

[28] Ferreira KM, Oliveira DS, Reggiolli MR. Qualidade dos alimentos consumidos por universitários de uma instituição de ensino superior de Mogi Guaçu/SP. Interciência \& Sociedade. 2014;3:77-86.

[29] Busato MA, Pedrolo C, Gallina LS, Rosa L. Ambiente e alimentação saudável: percepções e práticas de estudantes universitários. Semina: Ciências Biológicas e da Saúde. 2015;36:75-84.

[30] Faria NU, Rinaldi AEM, Abdala MC. Hábitos alimentares e sociabilidade no horário de almoço de estudantes universitários. Demetra: alimentação, nutrição e saúde. 2015; 10:539-554.

[31] Leibovich YH. Avaliação do consumo alimentar de estudantes frequentadores do Restaurante Universitário da UnB [dissertação]. Brasília: Universidade de Brasília; 2015.

[32] Rossetti FX. Consumo alimentar, estado nutricional e percepção de segurança alimentar e nutricional entre estudantes de uma universidade pública [dissertação]. Piracicaba: Universidade de São Paulo; 2015.

[33] Tanton J, Dodd LJ, Woodfield L, Mabhala M. Eating behaviours of british university students: a cluster analysis on a neglected issue. Advances in Preventive Medicine. 2015;2015:18.

[34] Perez PMP, Castro IRR, Franco AS, Bandoni DH, Wolkoff DB. Práticas alimentares de estudantes cotistas e não cotistas de uma universidade pública brasileira. Ciênc. Saúde Coletiva. 2016;21:531-542.

[35] Tassitano RM, Martins CML, Cabral PC, Mota J, Tenório MCM, Silva GAP. Psychosocial factors and physical activity as predictors of fruit and vegetable intake in college students. Rev. Nutr. 2016;29:173-183.

[36] Cardoso GA. Consumo alimentar e estilo de vida: um estudo longitudinal com estudantes universitários [tese]. Piracicaba: Universidade de São Paulo; 2016.

[37] Instituto Brasileiro de Geografia e Estatística - IBGE. Pesquisa de orçamentos familiares 2008-2009: análise do consumo alimentar pessoal no Brasil. Rio de Janeiro; 2011. 
[38] Gaino NM. Estado nutricional e disponibilidade de nutrientes e carotenóides para a população brasileira [dissertação]. Piracicaba: Universidade de São Paulo; 2012.

[39] Louzada MLC, Martins APB, Canella DS, Baraldi LG, Levy $\mathrm{RB}$, Claro RM, et al. Alimentos ultraprocessados e perfil nutricional da dieta no Brasil. Rev. Saúde Pública. 2015;49:1-11.

[40] Fernandes J, Arts J, Dimond E, Hirshberg S, Lofgren IE. Dietary factors are associated with coronary heart disease risk factors in college students. Nutr. Res. 2013;33:647-652.

[41] Claro RM, Santos MAS, Oliveira TP, Pereira CA, Szwarcwald CL, Malta DC. Consumo de alimentos não saudáveis relacionados a doenças crônicas não transmissíveis no Brasil: Pesquisa Nacional de Saúde, 2013. Epidemiol. Serv. Saúde. 2015;24:257-265.

[42] Brasil. Ministério da Saúde. Secretaria de Vigilância em Saúde. Vigitel Brasil 2014: vigilância de fatores de risco e proteção para doenças crônicas por inquérito telefônico. Brasília (DF); 2015.

[43] Jaime PC, Stopa SR, Oliveira TP, Vieira ML, Szwarcwald CL, Malta DC. Prevalência e distribuição sociodemográfica de marcadores de alimentação saudável, Pesquisa Nacional de Saúde, Brasil 2013. Epidemiol. Serv. Saúde. 2015;24:267-276.
[44] Assis MAA, Nahas MV. Aspectos motivacionais em programas de mudança de comportamento alimentar. Rev. Nutr. 1999;12:33-41.

[45] Pedraza DF. Padrões alimentares da teoria à prática - o caso do Brasil. Mneme - Revista Virtual de Humanidades. 2004;4:104-114.

[46] Dutra GF, Kaufmann CC, Pretto ADB, Albernaz EP. Sedentary lifestyle and poor eating habits in childhood: a cohort study. Ciênc. Saúde Coletiva. 2016;21:1051-1059.

[47] Verhoeven H. Determinants of fruit \& vegetable and fat intake in university students: a cross-sectional explanatory study [dissertação]. Bruxelas: Vrije Universiteit Brussel; 2013.

[48] Oliveira CS, Gordia AP, Quadros TMB, Campos W. Atividade física de universitários brasileiros: uma revisão de literatura. Rev. Aten. Saúde. 2014;12:71-77. 